\title{
A Comparison of MISiC Schottky-Diode Hydrogen Sensors Made by $\mathrm{NO}, \mathrm{N}_{2} \mathrm{O}$, or $\mathrm{NH}_{3}$ Nitridations
}

\author{
W. M. Tang, P. T. Lai, Senior Member, IEEE, C. H. Leung, Member, IEEE, and J. P. Xu
}

\begin{abstract}
MISiC Schottky-diode hydrogen sensors with gate insulator grown in three different nitridation gases (nitric oxide (NO), $\mathrm{N}_{2} \mathrm{O}$, and $\mathrm{NH}_{3}$ ) are fabricated. Steady-state and transient-response measurements are carried out at different temperatures and hydrogen concentrations using a computer-controlled measurement system. Experimental results show that these nitrided sensors have high sensitivity and can give a rapid and stable response over a wide range of temperature. This paper also finds that $\mathrm{N}_{2} \mathrm{O}$ provides the fastest insulator growth with good insulator quality and hence the highest sensitivity among the three nitrided samples. The $\mathrm{N}_{2} \mathrm{O}$-nitrided sensor can give a significant response even at a low $\mathrm{H}_{2}$ concentration of 48-ppm $\mathrm{H}_{2}$ in $\mathrm{N}_{2}$, indicating a potential application for detecting hydrogen leakage at high temperature. Moreover, the three nitrided samples respond faster than the control sample. At $300{ }^{\circ} \mathrm{C}$, the response times of the $\mathrm{N}_{2} \mathrm{O}$, $\mathrm{NO}$, and $\mathrm{NH}_{3}$-nitrided sample to the 48 -ppm $\mathrm{H}_{2}$ in $\mathrm{N}_{2}$ are 11, 11, and $37 \mathrm{~s}$, respectively, as compared to $65 \mathrm{~s}$ for the control sample without the gate insulator.
\end{abstract}

Index Terms-Hydrogen sensors, nitridation, silicon carbide.

\section{INTRODUCTION}

$\mathbf{T}$ HE FIRST SiC Schottky-diode hydrogen sensor was developed by Hunter et al. at National Aeronautics and Space Administration (NASA) Lewis Research Center in 1992 [1]. It was a simple Schottky-diode structure that had a catalytic metal Pd directly deposited on SiC. This structure could sensitively detect hydrogen but was not thermally stable [2], [3]. After heating for a long time, there was an interfacial reaction between $\mathrm{Pd}$ and $\mathrm{SiC}$, forming $\mathrm{Pd}$ silicide [2] and causing a change in sensor properties [4]. To provide a longterm high-temperature stability, different materials, fabrication techniques, and sensor structures were developed. NASA Lewis Research Center and Case Western Reserve University used alloys such as palladium chrome as the catalytic metal [5], while some researchers employed more thermally stable metallization such as tungsten. Diamond, amorphous, and polycrystalline barium strontium titanate (BST) have been used as a substrate to reduce the interfacial reaction [6]-[8]. On the other hand, a metal-insulator-semiconductor (MIS) structure involving the use of a gate insulator was developed to reduce the interfacial diffusion between the electrode and the substrate. The gate insulator can make the structure more stable for gas

Manuscript received December 20, 2005; revised May 11, 2006. The review of this paper was arranged by Editor K. Najafi.

W. M. Tang, P. T. Lai, and C. H. Leung are with the Department of Electrical and Electronic Engineering, the University of Hong Kong, Hong Kong (e-mail: laip@eee.hk.hk).

J. P. Xu is with the Department of Electronic Science and Technology, Huazhong University of Science and Technology, Wuhan, 430074 China

Digital Object Identifier 10.1109/TED.2006.879676 sensing. Several gate insulators such as $\mathrm{SnO}_{2}$ [9] and $\mathrm{SiO}_{2}$ [10]-[12] had been used, and were thermally grown in $\mathrm{O}_{2}$ ambient. These gate insulators provide some improvements on the sensor performance, but they are still not very stable after a long-duration high-temperature operation [9]. Since the sensitivity and stability of the sensor largely depend on the gate insulator, the development of a high-quality gate insulator for MISiC Schottky sensors has become an essential issue. An oxide growth in nitric oxide (NO) gas was then developed to improve the oxide reliability and reduce the interface states and oxide charges [13]. Currently, researchers are still seeking new methods to produce sensitive and stable sensors that can operate at very high temperature for a long time. In this paper, MISiC Schottky-diode hydrogen sensors with insulators grown in three different nitridation gases $\left(\mathrm{NO}, \mathrm{N}_{2} \mathrm{O}\right.$, and $\left.\mathrm{NH}_{3}\right)$ are studied. Measurements are performed to investigate the effects of different nitridation gases on the sensitivity, stability, and response speed of the sensors. Current-voltage $(I-V)$, voltage-time $(V-t)$, and current-time $(I-t)$ curves are measured for each sample and compared with each other. Some useful parameters such as change in barrier height and response time are extracted from the measured data.

\section{EXPERIMENTS}

An N-type (0001) Si-face 6H-SiC wafer that was manufactured by CREE Research was used in this paper. The $\mathrm{SiC}$ wafer had a $5-\mu \mathrm{m}$ epitaxial layer grown on heavily doped substrate, and the doping level of the epitaxial layer was $4 \times 10^{15} \mathrm{~cm}^{-3}$. The wafer was cleaned using the conventional Radio Corporation of America (RCA) method followed by a 20-s dipping in $1 \%$ hydrofluoric acid to remove the native oxide. When the furnace reached $900{ }^{\circ} \mathrm{C}$, the wafer was loaded into the furnace with $\mathrm{N}_{2}$ inside to prevent the wafer from premature oxidation. Then, nitrogen gas was closed, and $\mathrm{NO}$ was flown into the furnace to do nitridation for 4 min (denoted as NO sample). In order to investigate the effects of different nitridation gases on the sensor performance, another two sets of oxynitride were grown under the same conditions but with different nitridation gases. One had a oxynitride grown in nitrous oxide $\left(\mathrm{N}_{2} \mathrm{O}\right)$, and the other in ammonia $\left(\mathrm{NH}_{3}\right)$ (denoted as $\mathrm{N} 2 \mathrm{O}$ and $\mathrm{NH} 3$, respectively). Moreover, a sample without any oxide layer was also fabricated as the control. All the samples were then annealed in $\mathrm{N}_{2}$ at $900{ }^{\circ} \mathrm{C}$ for 5 min to eliminate strains and defects, and improve the quality of the insulator. Electrodes were then formed by dc-magnetron sputtering with a substrate temperature of $350{ }^{\circ} \mathrm{C}$. The front electrode of $10-\mathrm{nm} \mathrm{TaSi} i_{x}$ and $100-\mathrm{nm} \mathrm{Pt}$ in the form of dots with $0.5-\mathrm{mm}$ diameter was 


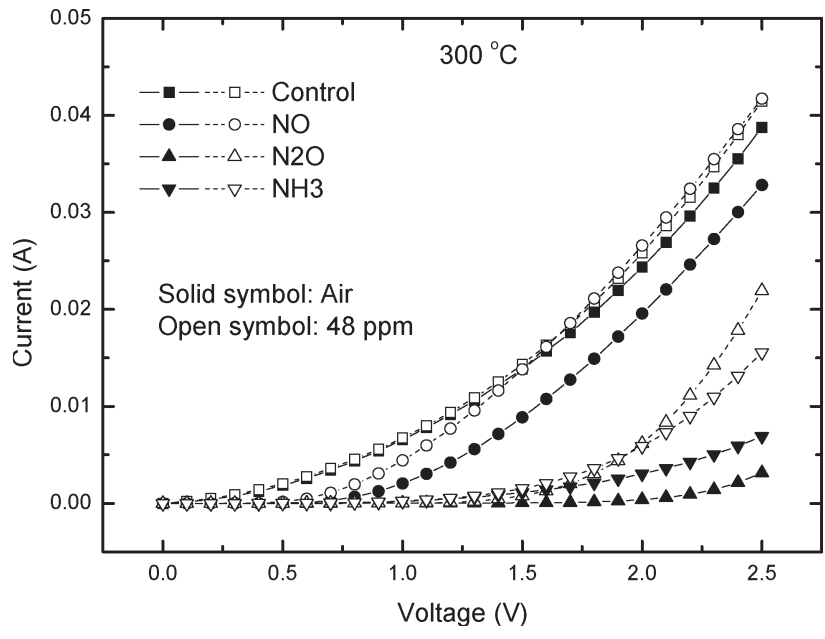

Fig. 1. $I-V$ curves of the samples in air and in $48-\mathrm{ppm}_{2}$ in $\mathrm{N}_{2}$ at $300{ }^{\circ} \mathrm{C}$.

deposited on the wafer surface through a stainless-steel mask. The back electrode of 200-nm TaSi $x$ and 400-nm Pt was formed after etching off the oxide at the wafer back. The purpose of adding $\operatorname{TaSi}_{x}$ was to improve the stability of the Pt layer [14] and to make the electrodes more adhesive to the insulator and the $\mathrm{SiC}$ substrate [15]. The samples underwent metal annealing in a furnace at $550^{\circ} \mathrm{C}$ with $\mathrm{N}_{2}$ flowing inside $(1000 \mathrm{ml} / \mathrm{min})$ for $20 \mathrm{~min}$.

After fabrication of the sensors, their hydrogen-sensing properties were investigated. Steady-state and transient measurements were carried out using a computer-controlled measurement system to study the sensitivity and response speed of the sensors. The measurement system mainly consisted of two parts: the gas-mixing supply system and the parameter-testing system. A thermostat, an HP4145B semiconductor parameter analyzer, and three digital gas flow controllers (DFCs) were connected to a computer and controlled by software programs. The test sample was placed in a stainless steel closed chamber inside the thermostat, and gases were injected into the chamber through the DFCs. The flow rates of the DFCs were controlled by the sizes of their valves, which were controlled by applied dc voltages. Thus, by adjusting the applied voltage of each DFC, the flow rates of hydrogen and nitrogen were controlled, and hence, different hydrogen concentrations were achieved. The thermostat could provide a wide temperature range from room temperature to $600{ }^{\circ} \mathrm{C}$. The computer programs set different measurement conditions by altering the temperature of the thermostat and the flow rates of different gases, and measurement results were automatically saved in the computer. The measurement range of the experimental setup was 29 to $1000 \mathrm{ppm} \mathrm{H}_{2}$ in $\mathrm{N}_{2}$. In order to test the sensors in a practical environment, the system was not first purged in nitrogen, and no precaution was done to eliminate the effects of water vapor.

\section{RESUlTS AND Discussion}

Fig. 1 shows the $I-V$ curves of the control and nitrided samples measured in air and in 48-ppm $\mathrm{H}_{2}$ in $\mathrm{N}_{2}$ at $300^{\circ} \mathrm{C}$. In order to obtain a steady response, the $I-V$ curves for $\mathrm{H}_{2}$ ambient are measured at $150 \mathrm{~s}$ after the introduction of the gases. The $I-V$

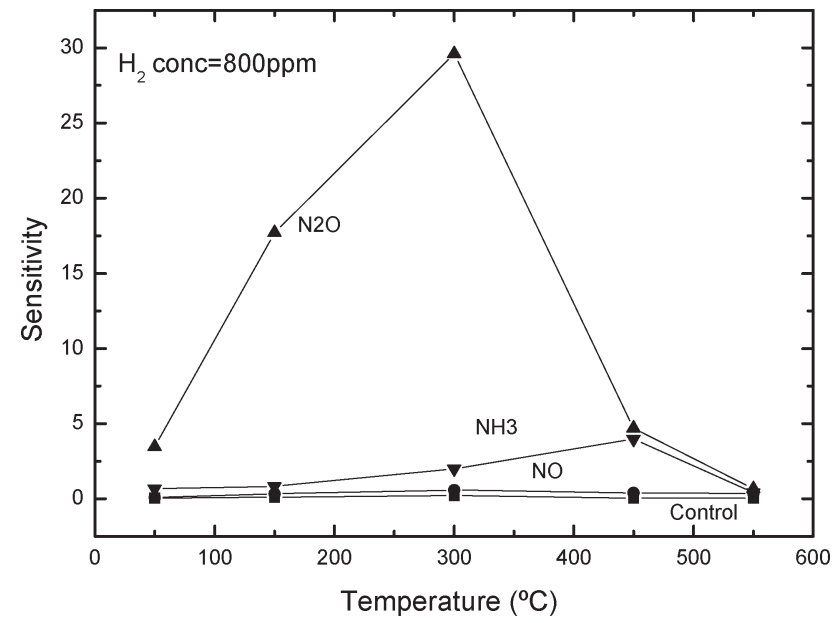

Fig. 2. Sensitivity of the samples at different temperatures when the test environment is changed from air to $800-\mathrm{ppm}_{2}$ in $\mathrm{N}_{2}$ (bias voltage $=2 \mathrm{~V}$ ).

curves shift to the left upon exposure to $\mathrm{H}_{2}$ due to the formation of a polarized layer at the electrode-insulator interface. When hydrogen-containing molecules come to the front electrode, they dissociate at the surface of the electrode and form hydrogen atoms. These hydrogen atoms then diffuse through the electrode to the surface of the insulator and form a polarized layer at the electrode-insulator interface [16]. This polarized layer provides an extra electric field to lower the Schottky barrier. In Fig. 1, the N2O sample has the largest turn-on voltage, while the control sample has the smallest. Thicker insulator giving larger turn-on voltage can be confirmed by ellipsometric measurements: The insulator thicknesses of the $\mathrm{NO}, \mathrm{N} 2 \mathrm{O}$, and $\mathrm{NH} 3$ samples before the formation of electrodes are 1.96, 2.25 , and $2.22 \mathrm{~nm}$, respectively. The thickest insulator in the N2O sample can be ascribed to two reasons. First, during the nitridation process, $\mathrm{N}_{2} \mathrm{O}$ dissociates quickly into $\mathrm{NO}, \mathrm{O}_{2}$, and $\mathrm{N}_{2}$ [17]. The resulting $\mathrm{O}_{2}$ facilitates the oxidation of the substrate. Second, the decomposition of $\mathrm{N}_{2} \mathrm{O}$ is an exothermic reaction [18], which raises the nitridation temperature and hence increases the growth rate of the insulator.

Fig. 2 depicts the sensitivity of the control and nitrided samples at different temperatures when the test chamber environment is changed from air to 800-ppm $\mathrm{H}_{2}$ in $\mathrm{N}_{2}$. The reported temperature refers to the temperature of the thermostat, which should be close to the sensor-surface temperature after some time. The sensitivity is defined as $\left(I_{\mathrm{H}_{2}}-I_{\text {air }}\right) / I_{\text {air }}$, where $I_{\mathrm{H}_{2}}$ and $I_{\text {air }}$ are the currents measured in hydrogen and air, respectively. The applied voltage is $2 \mathrm{~V}$. The sensitivities of all samples initially increase with temperature but then decrease as the temperature further increases. This phenomenon can be explained as follows. When temperature increases, the hydrogen under higher pressure will bombard the surface of the electrode more frequently. Hence, more hydrogen molecules can adsorb on the surface of the electrode and decompose faster into hydrogen atoms, giving higher sensitivity. On the other hand, the oxygen attached to the surface of the electrode (when the sensor is exposed to air) can react with the hydrogen atoms to form hydroxyl ions and water [19], [20]. The formation rates of these products increase rapidly at high temperature, thus decreasing the sensitivity. Further increasing temperature can 
also activate the traps inside the insulator as well as the traps at the metal/insulator interface to increase the $I_{\text {air }}$ of the device and hence reduce the sensitivity more [7].

The sensitivities of the nitrided samples are higher than that of the control sample over the whole temperature range from $50{ }^{\circ} \mathrm{C}$ to $550{ }^{\circ} \mathrm{C}$. The improved sensitivity of the nitrided samples is partly due to the incorporation of nitrogen in the insulator, which forms strong triple bonds with the dangling bonds of silicon. Besides improving the interfacial diffusion barriers and hence device reliability [21], [22], these strong $\mathrm{Si} \equiv \mathrm{N}$ bonds can also decrease the interfacial strain and remove fixed oxide charges, carbon-related interface traps [23], carbon atoms, and clusters at the interface [24]. With better interfacial properties, the nitrided samples should have a better response to external stimuli. The enhanced sensitivity of the nitrided samples is also due to the presence of an insulator layer, which reduces $I_{\text {air }}$. Samples with an insulator layer have smaller $I_{\text {air }}$ and larger barrier-height modulation [25] and hence higher sensitivity. Among the three nitrided samples, the $\mathrm{N} 2 \mathrm{O}$ sample has the highest sensitivity while the NO sample has the lowest. This is mainly due to the thickest insulator in the former. It should be noted that although the $\mathrm{NH} 3$ sample has nearly the same insulator thickness as the $\mathrm{N} 2 \mathrm{O}$ sample, its sensitivity is much lower. This is because the hydrogen species released during the $\mathrm{NH}_{3}$ nitridation is well known to generate many electron traps in the insulator [26] which can increase $I_{\text {air }}$ (see Fig. 1), thus reducing the device sensitivity. The better sensitivity of the $\mathrm{N} 2 \mathrm{O}$ sample could also be due to the exothermic nature of $\mathrm{N}_{2} \mathrm{O}$ decomposition, which increases the temperature inside the furnace. As a result, more $\mathrm{N}_{2} \mathrm{O}$ can be decomposed, and thus, more nitrogen can be incorporated in the insulator to remove its traps [18], thus improving the sensitivity. Moreover, the nitrogen peak at the interface of $\mathrm{N}_{2} \mathrm{O}$-grown oxide is wider and shifts toward the oxide side than that of NO-grown oxide [27]. This can result in a reduction of fast traps and hence higher sensitivity. In general, $I_{\text {air }}$ increases with temperature because at higher temperature, more electrons have sufficient energy to overcome the potential barrier and flow through the Schottky diode. However, $I_{\text {air }}$ of the control and NO samples decrease as temperature increases (not shown). This is probably due to the oxidation of $\mathrm{SiC}$ in air at high temperature, forming an insulator layer at the interface, which blocks the current flow. For the other two samples with thicker built-in insulator separating $\mathrm{Pt}$ and $\mathrm{SiC}$, such oxidation can be greatly suppressed.

The sensitivity of the nitrided samples upon exposure to different $\mathrm{H}_{2}$ concentrations is compared with that of the control sample in Fig. 3. At $300{ }^{\circ} \mathrm{C}$ under a forward voltage of $2 \mathrm{~V}$, the sensitivities of all the samples increase with hydrogen concentration. The control sample has a sensitivity of $6 \%$ at 48-ppm $\mathrm{H}_{2}$ in $\mathrm{N}_{2}$, which gets saturated very quickly at around $429 \mathrm{ppm}$ with a value of about $19 \%$. The nitrided samples show a higher sensitivity than the control sample because thermal nitridation improves the interfacial properties of the sensors and also creates an insulator layer, which lowers $I_{\text {air }}$. Among the three nitridations, the $\mathrm{N}_{2} \mathrm{O}$ nitridation provides the largest improvement in sensitivity. The corresponding sample can give a significant sensitivity of $1590 \%$ at a low $\mathrm{H}_{2}$ concentration of

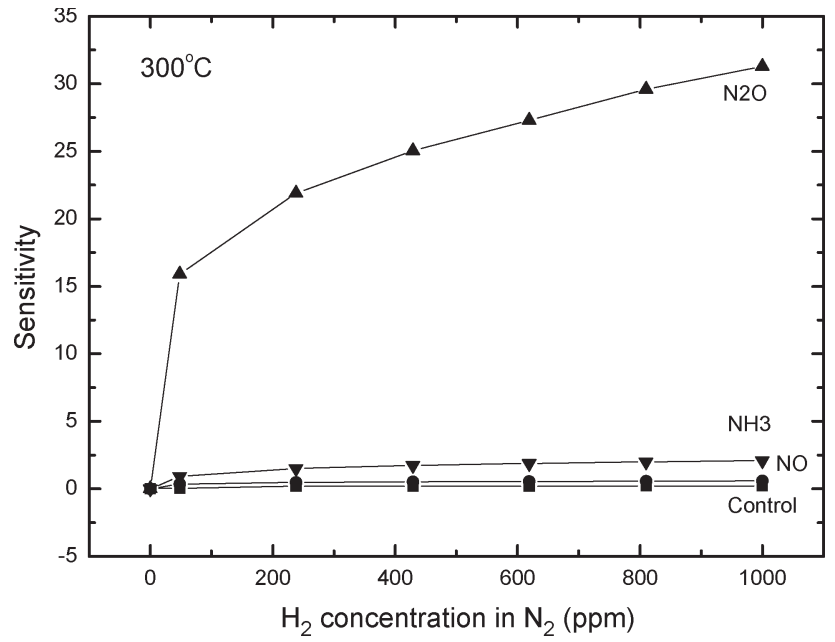

Fig. 3. Sensitivity of the samples (bias voltage $=2 \mathrm{~V}$ ) upon exposure to different $\mathrm{H}_{2}$ concentrations in $\mathrm{N}_{2}$ at $300{ }^{\circ} \mathrm{C}$.

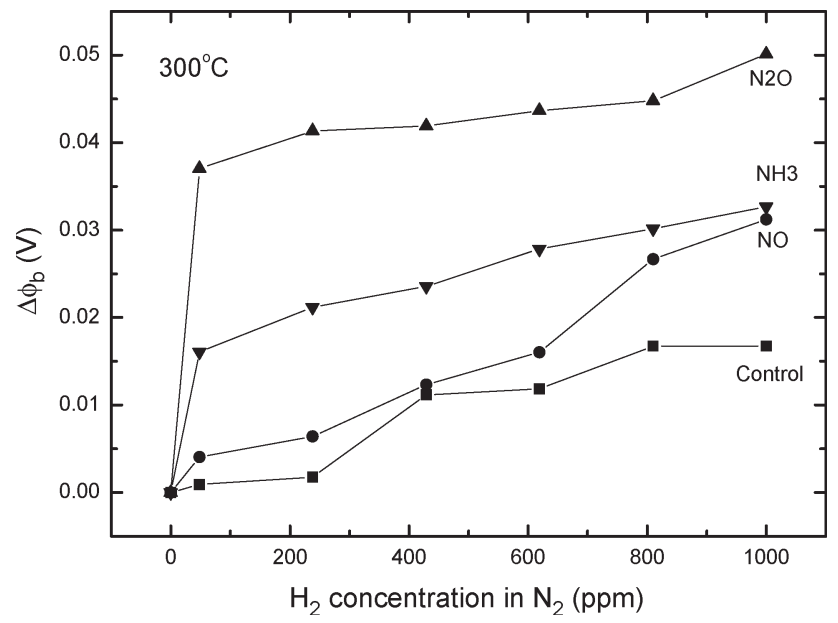

Fig. 4. Barrier-height variation of the samples upon exposure to different $\mathrm{H}_{2}$ concentrations in $\mathrm{N}_{2}$ at $300{ }^{\circ} \mathrm{C}$.

$48 \mathrm{ppm}$, and the sensitivity continuously increases to $2960 \%$ at $800 \mathrm{ppm}$, without getting saturated even at $1000 \mathrm{ppm}$.

Fig. 4 shows the change in the barrier height of the nitrided and control samples upon exposure to different $\mathrm{H}_{2}$ concentrations. There are many factors affecting the Schottky barrier height of the devices, such as the metal work function, surface roughness, interface-state density, etc. The barrier height $\phi_{b}$ is calculated using the following formula [28]:

$$
\phi_{b}=-\frac{k T}{q} \ln \left(\frac{I_{o}}{A A^{* *} T^{2}}\right)
$$

where $k$ is the Boltzmann constant, $T$ is the temperature in $\mathrm{K}, q$ is the electron charge, $I_{o}$ the saturation current, $A$ is the junction area, and $A^{* *}$ is the effective Richardson constant. $I_{O}$ (in air or in $\mathrm{H}_{2}$ ) can be found from the corresponding $y$-intercept of the graph of $\ln (I)$ versus $V$. When the hydrogen concentration increases, the barrier height of the sensor decreases, and the barrier-height variation defined as $\phi_{b}$ (air) $-\phi_{b}\left(\mathrm{H}_{2}\right)$ increases. It is because when more hydrogencontaining molecules come to the front electrode, more 


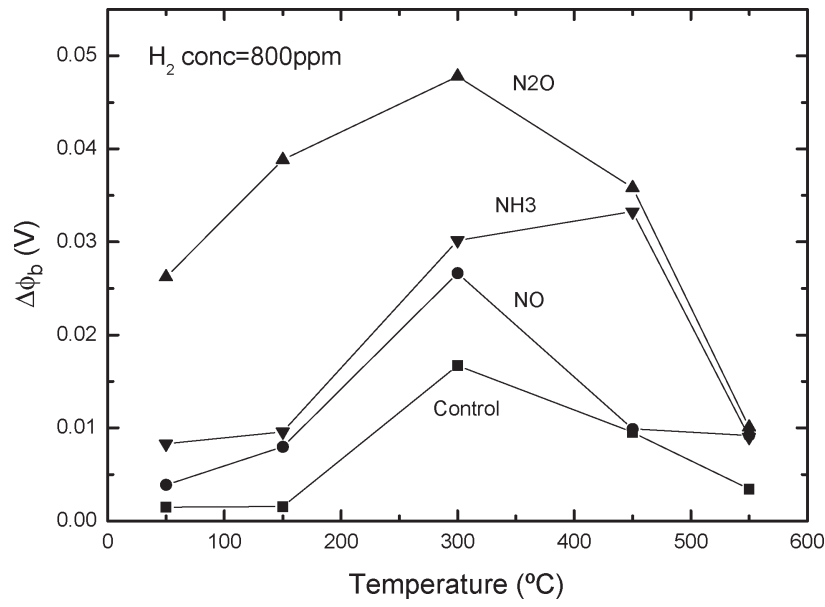

Fig. 5. Barrier-height variation of the samples upon exposure to 800-ppm $\mathrm{H}_{2}$ at different temperatures.

hydrogen atoms can be absorbed at the electrode-insulator interface to form a polarized layer. This polarized layer causes a significant barrier-lowering effect. Upon hydrogen exposure, the nitrided samples give a larger change in barrier height than the control sample, and hence are more sensitive. This fact demonstrates that the gate-insulator layer plays an important role in enhancing the sensor performance. Among the three nitridation gases, $\mathrm{N}_{2} \mathrm{O}$ can cause the sensor to have the largest change in barrier height. This further confirms that thicker insulator results in a larger change in barrier height and hence higher sensitivity. The variation of the barrier height is caused by not only change of hydrogen concentration but also temperature change. Fig. 5 demonstrates the change in barrier height as a function of temperature. When the temperature increases from $50{ }^{\circ} \mathrm{C}$ to $300{ }^{\circ} \mathrm{C}$, the change of the barrier height increases for the following reason. At high temperature, more adsorbed hydrogen can diffuse through the electrode to the electrode/insulator interface and hence produce a larger electric field to lower the Schottky barrier more. When the temperature is further raised from $300{ }^{\circ} \mathrm{C}$ to $550{ }^{\circ} \mathrm{C}$, the change in barrier height becomes smaller. This is because at higher temperatures, hydrogen atoms will react with oxygen atoms more quickly at the surface of the electrode, and thus fewer hydrogen atoms can diffuse to the interface to reduce the barrier height.

Presented in Figs. 6-8 are the responses of the samples in the form of a voltage shift $\Delta V$, which is defined as $V$ (in air)- $V$ (in $\mathrm{H}_{2}$ ) for a given bias current. These experimental results were obtained by performing transient measurements whereby $\mathrm{H}_{2}$ was turned on for $200 \mathrm{~s}$ and then turned off for $200 \mathrm{~s}$ in one cycle, and the cycle was repeated many times for stable results. When $\mathrm{H}_{2}$ was turned off, the air was inside the chamber. In Fig. 6, $\Delta V$ of all the samples increases as the forward current increases. This result is obvious as the current and voltage of the devices are exponentially related to each other. The $I-V$ curve shifts more to the left as the bias current increases. However, the voltage shift of the N2O sample does not increase significantly as the current increases. It is because the devices with a thick insulator have a large turn-on voltage, and the slope of the linear region of the $I-V$ curve is usually very large. Hence, $\Delta V$ is less dependent on the applied

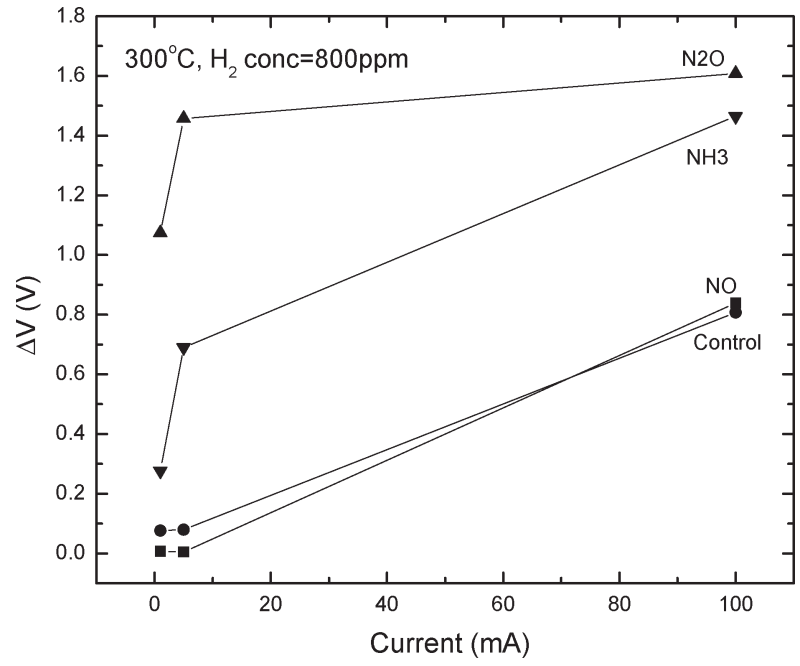

Fig. 6. Voltage shift versus bias current of the samples upon exposure to 800-ppm $\mathrm{H}_{2}$ in $\mathrm{N}_{2}$ at $300{ }^{\circ} \mathrm{C}$.

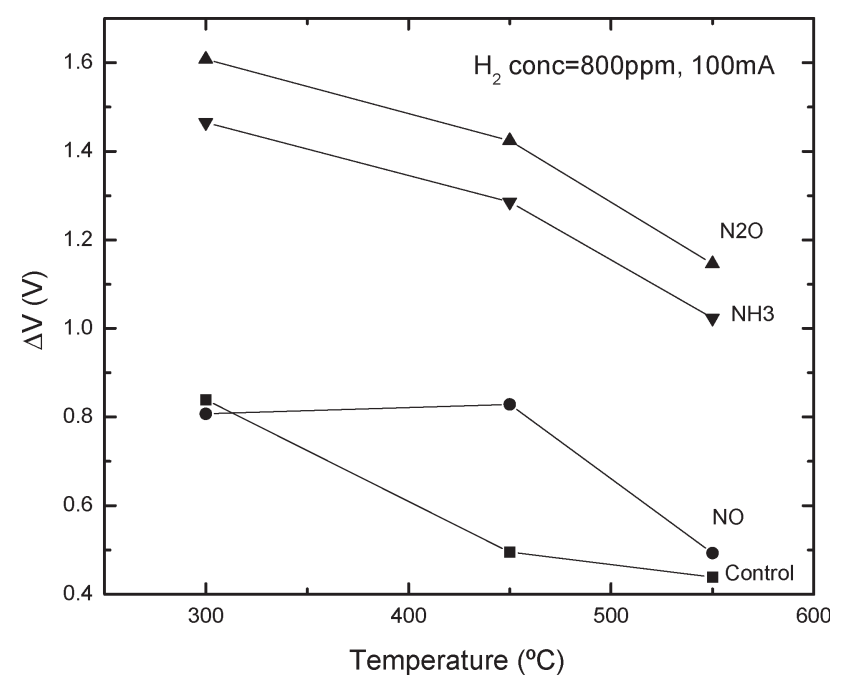

Fig. 7. Voltage shift versus temperature of the samples upon exposure to 800 -ppm $\mathrm{H}_{2}$ in $\mathrm{N}_{2}$ under a bias current of $100 \mathrm{~mA}$.

forward current. Fig. 7 shows that under a fixed forward current (100 $\mathrm{mA})$ and hydrogen concentration (800 ppm), $\Delta V$ decreases as temperature increases. This is due to the fact that at higher temperatures, the reduced hydrogen coverage at the interface mentioned earlier causes a decreased change in barrier height, thus giving a smaller $\Delta V$.

The excellent response of the nitrided samples especially the $\mathrm{N} 2 \mathrm{O}$ sample is further confirmed by the transient-responsemeasurement results. Fig. 8 shows the adsorption transient behavior of the samples upon exposure to 48-ppm $\mathrm{H}_{2}$ in $\mathrm{N}_{2}$ at $450{ }^{\circ} \mathrm{C}$. The voltage shift increases with hydrogen concentration because more hydrogen-containing molecules absorbed at the electrode-insulator interface can form a stronger polarized layer, providing a larger electric field to give a larger voltage shift. The voltage shifts of the nitrided samples are greater than that of the control sample, with the N2O sample having the largest voltage shift. This phenomenon, like that in Fig. 1, is mainly due to the thicker insulator layer in the nitrided samples, resulting in larger $\Delta \phi_{b}$ and hence larger voltage shift. 


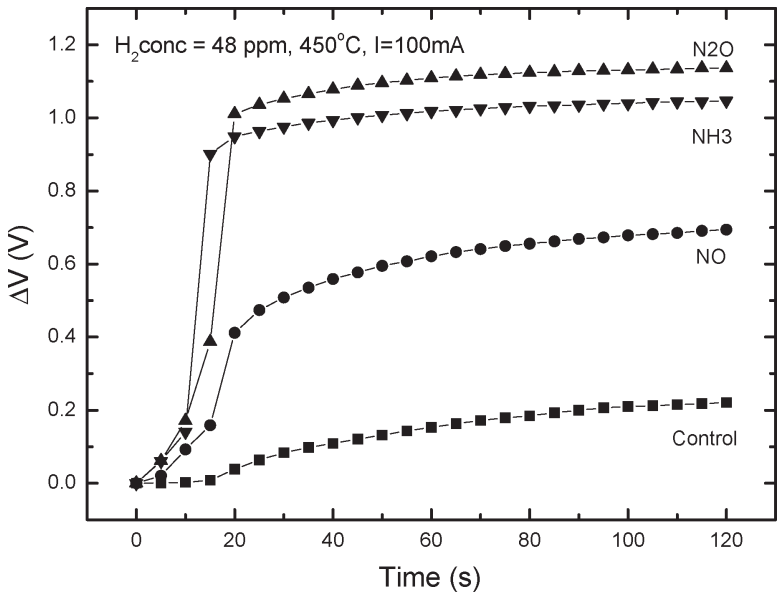

Fig. 8. Absorption transient behavior of the samples upon exposure to 48-ppm $\mathrm{H}_{2}$ in $\mathrm{N}_{2}$ (at time $=0 \mathrm{~s}$ ) at $450{ }^{\circ} \mathrm{C}$ for a bias current of $100 \mathrm{~mA}$.

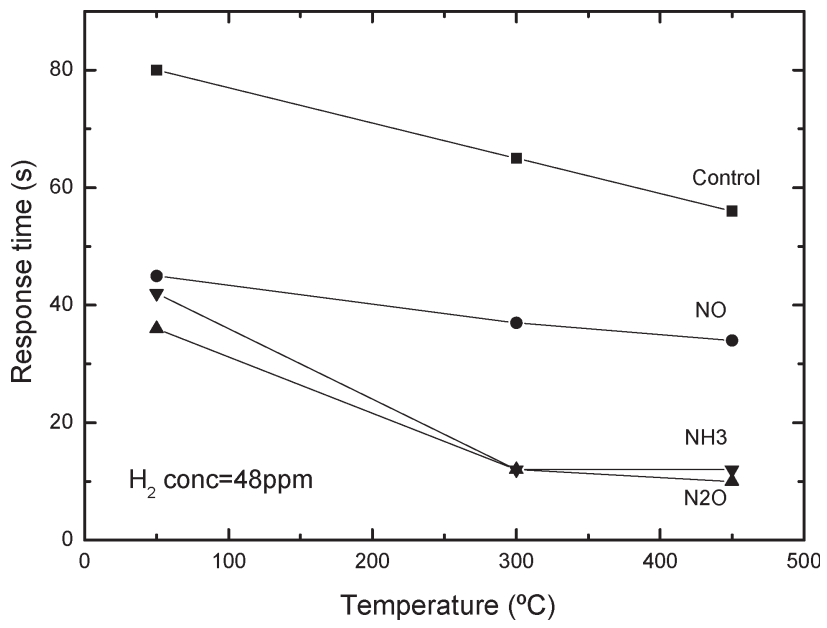

Fig. 9. Response time versus temperature of the samples.

The response time, which is defined as $e^{-1}$ times the final steady-state value, can be obtained from the transient-response curves. As shown in Fig. 9, the response time of all the samples decreases with the increasing operating temperature because high temperature enables faster hydrogen decomposition and diffusion, and hence faster response. The response time of the control sample to $48-\mathrm{ppm} \mathrm{H}_{2}$ decreases from $80 \mathrm{~s}$ at $50{ }^{\circ} \mathrm{C}$ to $56 \mathrm{~s}$ at $450{ }^{\circ} \mathrm{C}$. On the other hand, the response times of the nitrided samples at $50{ }^{\circ} \mathrm{C}$ are nearly half that of the control sample, and can be one-fifth at higher temperatures. The graph also shows that the response times of the $\mathrm{N} 2 \mathrm{O}$ and $\mathrm{NH} 3$ samples are quite close, which should be related to the similar morphologies of their Pt films [29], [30] that are both grown on an amorphous insulator with the same thickness. The atomic force microscopy (AFM) showed that the average grain sizes of the $\mathrm{N} 2 \mathrm{O}$ and $\mathrm{NH} 3$ samples were 18.8 and $20.8 \mathrm{~nm}$, respectively, as compared to 22.1 and $24.3 \mathrm{~nm}$ for the $\mathrm{NO}$ and control samples. As a result, more grain boundaries in the $\mathrm{N} 2 \mathrm{O}$ and $\mathrm{NH} 3$ samples can facilitate the diffusion of hydrogen atoms, giving them a faster response. A further study by transmission electron microscopy is being carried out to provide a clearer picture. The response time also decreases with increasing hydrogen concentration because it is related to the hydrogen absorption rate, which is controlled by how fast hydrogen atoms are absorbed at the electrode/insulator interface. Higher hydrogen concentration results in faster diffusion of hydrogen atoms to the interface and hence gives a faster response. In general, recovery time is longer than the response time because more time is needed for the hydrogen atoms to diffuse to the electrode surface and then recombine together to form hydrogen gas.

\section{CONCLUSION}

A thin oxynitride/nitride that is grown in $\mathrm{NO}, \mathrm{N}_{2} \mathrm{O}$, or $\mathrm{NH}_{3}$ at low temperature is successfully used as the gate insulator for fabricating MISiC Schottky-diode hydrogen sensors. Experimental results demonstrate that these nitrided sensors have high sensitivity, high stability, and fast response over a wide range of temperature. The excellent hydrogen-sensing characteristics of these devices are attributed to the incorporation of nitrogen in the devices, which can result in fewer interface states and oxide charges and better interfacial diffusion barriers. Among the three nitrided sensors, the sensor with thin $\mathrm{N}_{2} \mathrm{O}$-grown oxynitride as gate insulator has the highest sensitivity. This is mainly due to its thicker insulator, which gives a smaller $I_{\text {air }}$ and hence higher sensitivity. Moreover, the exothermic decomposition of $\mathrm{N}_{2} \mathrm{O}$ during nitridation results in more $\mathrm{NO}$ and hence more nitrogen incorporated into the insulator to improve the sensor performance. These sensors have potential applications for detecting hydrogen leakage in harsh hightemperature environments.

\section{REFERENCES}

[1] G. W. Hunter, P. G. Neudeck, and G. D. Jefferson et al., "The development of hydrogen sensors technology at NASA Lewis Research Centre," in Proc. 4th Ann. Space Syst. Health Manage. Technol. Conf., Cincinnati, OH, NASA Technical Memo.106141, Nov. 1992, pp. 1-18.

[2] G. W. Hunter, P. G. Neudeck, L.-Y. Chen, D. Knight, C.-C. Liu, and Q. H. Wu, "Silicon Carbide-Based hydrogen and hydrocarbon gas detection," presented at the 31st Joint Propulsion Conference and Exhibit, San Diego, CA, Jul. 10-12, 1995, AIAA Paper 95-2647, pp. 1-12.

[3] L.-Y. Chen, G. W. Hunter, P. G. Neudeck, G. Bansal, J. B. Petit, D. Knight, C.-C. Liu, and Q. H. Wu, "Electronic and interfacial properties of Pd/6HSiC Schottky diode gas sensors," in Proc. 3rd Int. High Temp. Electron. Conf., Albuquerque, NM, Jun. 9-14, 1996, vol. 1, p. X17-24.

[4] G. W. Hunter, P. G. Neudeck, and L.-Y. Chen et al., "SiC-based Schottky diode gas sensor," in Proc. 7th Int. Conf. Silicon Carbide, III-Nitrides Related Mater, Stockholm, Sweden, 1997, vol. 2, pp. 1093-1096.

[5] G. W. Hunter, P. G. Neudeck, L. Y. Chen, D. Knight, C. C. Liu, and Q. H. Wu, "Microfabricated chemical sensors for safety and emission control applications," in Proc. 17th Digital Avionics Syst. Conf., 1998, vol. 1, pp. D11/1-D11/8.

[6] W. P. Kang, Y. Gurbuz, J. L. Davidson, and D. V. Kerns, "A polycrystalline diamond thin-film-based hydrogen sensor," Sens. Actuators B, Chem., vol. 25, no. 1-3, pp. 421-425, Apr. 1995.

[7] X. F. Chen, W. G. Zhu, and O. K. Tan, "Microstructure, dielectric properties and hydrogen gas sensitivity of sputtered amorphous $\mathrm{Ba}_{0.67} \mathrm{Sr}_{0.33} \mathrm{TiO}_{3}$ thin film," Mater. Sci. Eng. B, vol. B77, no. 2, pp. $177-$ 184, Aug. 2000.

[8] G. W. Dietz, M. Schumacher, R. Waser, S. K. Streiffer, C. Basceri, and A. I. Kingon, "Leakage currents in $\mathrm{Ba}_{0.67} \mathrm{Sr}_{0.33} \mathrm{TiO}_{3}$ thin films for ultrahigh-density dynamic random access memories," J. Appl. Phys., vol. 82, no. 5, pp. 2359-2364, Sep. 1997.

[9] G. W. Hunter, P. G. Neudeck, and M. Gray et al., "SiC-based gas sensor development," Mater. Sci. Forum, vol. 338-342, pp. 1439-1442, 2000.

[10] L.-Y. Chen, G. W. Hunter, and P. G. Neudeck et al., "Comparison of interfacial and electronic properties of annealed $\mathrm{Pd} / \mathrm{SiC}$ and $\mathrm{Pd} / \mathrm{SiO}_{2} / \mathrm{SiC}$ Schottky diodes," J. Vac. Sci. Technol. A, Vac. Surf. Films, vol. 15, no. 3, pp. 1228-1234, May 1997. 
[11] S. Zangooie, H. Arwin, and I. Lundstrom et al., "Ozone treatment of SiC for improved performance of gas sensitive Schottky diodes," Mater. Sci. Forum, vol. 338-342, pp. 1085-1088, 2000.

[12] P. Tobias, A. Baranzahi, and A. L. Spetz et al., "Fast chemical sensing with metal-insulator silicon carbide structures," IEEE Electron Device Lett., vol. 18, no. 6, pp. 287-289, Jun. 1997.

[13] J. P. Xu, P. T. Lai, D. G. Zhong, and C. L. Chan, "Improved hydrogensensitive properties of MISiC Schottky Sensor with thin NO-Grown oxynitride as gate insulator," IEEE Electron Device Lett., vol. 24, no. 1, pp. 13-15, Jan. 2003.

[14] A. Baranzanhi, A. Lloyd Spetz, and I. Lundstrom, "Reversible hydrogen annealing of metal-oxide-silicon carbide devices at high temperatures," Appl. Phys. Lett., vol. 67, no. 21, pp. 3203-3205, Nov. 1995.

[15] A. L. Spetz, P. Tobias, A. Baranzahi, P. Martensson, and I. Lundstrom, "Current status of silicon carbide based high-temperature gas sensors," IEEE Trans. Electron Devices, vol. 46, no. 3, pp. 561-566, Mar. 1999.

[16] L.-G. Ekedahl, M. Eriksson, and I. Lundstrom, "Hydrogen sensing mechanisms of metal-insulator interfaces," Acc. Chem. Res., vol. 31, no. 5, pp. 249-256, 1998.

[17] P. Jamet, S. Dimitrijev, and P. Tanner, "Effects of nitridation in gate oxides grown on 4H-SiC," J. Appl. Phys., vol. 90, no. 10, pp. 5058-5063, Nov. 2001.

[18] K. A. Ellis and R. A. Buhrman, "Furnace gas-phase chemistry of silicon oxynitridation in $\mathrm{N}_{2} \mathrm{O}$," Appl. Phys. Lett., vol. 68, no. 12, pp. 1696-1698, Mar. 1996.

[19] C. C. Cheng, Y. Y. Tsai, K. W. Lin, H. I. Chen, and W. C. Liu, "Hydrogen sensing properties of a Pt-oxide- $\mathrm{Al}_{0.24} \mathrm{Ga}_{0.76} \mathrm{As}$ high-electron-mobility transistor," Appl. Phys. Lett., vol. 86, no. 11, p. 112103, Mar. 2005.

[20] W. C. Liu, K. W. Lin, C. K. Wang, C. C. Cheung, and C. T. Lu, "A new $\mathrm{Pt} /$ Oxide/ $/ \mathrm{In}_{0.49} \mathrm{Ga}_{0.51} \mathrm{P}$ MOS Schottky diode hydrogen sensor," IEEE Trans. Electron Devices, vol. 23, no. 11, pp. 640-642, Nov. 2002.

[21] H. F. Li, S. Dimitrijev, and H. B. Harrison, "Improved reliability of NOnitrided $\mathrm{SiO}_{2}$ grown on p-type 4H-SiC," IEEE Electron Device Lett., vol. 19, no. 8, pp. 279-281, Aug. 1998.

[22] H. B. Harrison, H. F. Li, S. Dimitrijev, and P. Tanner, Fundamental Aspects of Ultrathin Dielectrics on Si-Based Devices, vol. 47, E. Garfunkel, E. Gusev, and A. Vul, Eds. Dordrecht, The Netherlands: Kluwer, 1996.

[23] G. Y. Chung, C. C. Tin, J. R. Williams, K. McDonald, M. Di Ventra, S. T. Pantelides, L. C. Feldman, and R. A. Weller, "Effect of nitric oxide annealing on the interface trap densities near the band edges in the $4 \mathrm{H}$ polytype of silicon carbide," Appl. Phys. Lett., vol. 76, no. 13, pp. 17131715, Mar. 2000

[24] P. Tanner, S. Dimitrijev, H. F. Li, D. Sweatman, K. E. Prince, and H. B. Harrison, "SIMS analysis of nitrided oxides grown on $4 \mathrm{H}-\mathrm{SiC}$," J. Electron. Mater, vol. 28, no. 2, pp. 109-111, 1999.

[25] L. W. Chau and P. His-Jen et al., "Hydrogen sensitive characteristics of a novel Pd/InP MOS Schottky diode hydrogen sensor," IEEE Trans. Electron Devices, vol. 48, no. 9, pp. 1938-1944, Sep. 2001.

[26] S. K. Lai, D. W. Dong, and A. Hartstein, "Effects of ammonia anneal on electron trappings in silicon dioxide," J. Electrochem. Soc., vol. 129, no. 9, pp. 2042-2044, Sep. 1982.

[27] S. Dimitrijev, P. Tanner, and H. B. Harrison, "Slow-trap profiling of NO and $\mathrm{N}_{2} \mathrm{O}$ nitrided oxides grown on $\mathrm{Si}$ and $\mathrm{SiC}$ substrates," Microelectron. Reliab., vol. 39, no. 4, pp. 441-449, Apr. 1999.

[28] S. M. Sze, Semiconductor Devices Physics and Technology. NY: Wiley, 1981.

[29] J. W. Medlin, A. E. Lutz, R. Bastasz, and A. H. McDanie, "The response of palladium metal-insulator-semiconductor devices to hydrogen-oxygen mixtures: comparisons between kinetic models and experiment," Sens. Actuators B, Chem., vol. 96, no. 1/2, pp. 290-297, Nov. 2003

[30] Y. I. Chou, C. M. Chen, W. C. Liu, and H. I. Chen, "A new Pd-InP Schottky hydrogen sensor fabricated by electrophoretic deposition with Pd nanoparticles," IEEE Electron Device Lett., vol. 26, no. 2, pp. 62-65, Feb. 2005.

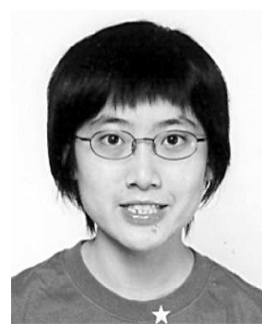

W. M. Tang received the B.Eng. degree (first class honors) and M.Phil. degrees in electrical and electronic engineering from the University of Hong Kong, Hong Kong, in 2002 and 2004, respectively, where she is currently working toward a Ph.D. degree.

Her research interest is on electronic devices, especially in the area of sensors.

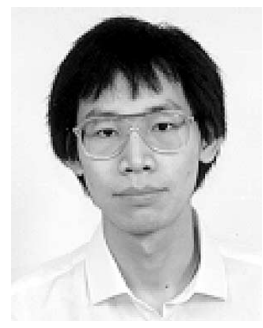

P. T. Lai (M'90-SM'04) received the B.Sc.(Eng.) degree from the University of Hong Kong, Hong Kong. His Ph.D. research at the University of Hong Kong, was on the design of small-sized MOS transistor with emphasis on narrow-channel effects. The work involved the development of both analytical and numerical models, the study of this effect in relation to different isolation structures, and the development of efficient numerical algorithms for device simulation.

He worked as a Postdoctoral Fellow with the University of Toronto. He proposed and implemented a novel self-aligned structure for bipolar transistor and designed and implemented an advanced polyemitter bipolar process with emphasis on self-alignment and trench isolation. His current research interests are on thin gate dielectrics for FET devices based on $\mathrm{Si}, \mathrm{SiC}, \mathrm{GaN}, \mathrm{Ge}$, and organics and microsensors for detecting gases, heat, light, and flow.

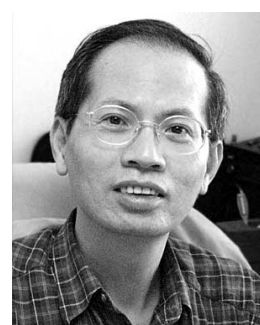

C. H. Leung (S'75-M'76) received the B.Sc. Eng. and $\mathrm{Ph} . \mathrm{D}$. degrees from the University of Hong Kong, Hong Kong, and the M.Eng. degree from McGill University, Montreal, QC, Canada, all in electrical engineering.

$\mathrm{He}$ worked for several years in industry. Since 1986, he has been working with the Department of Electrical and Electronic Engineering, University of Hong Kong, Hong Kong. His research interests include pattern recognition, quantum computation, and electronic circuits.

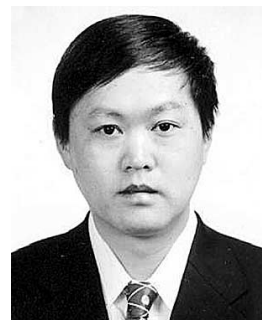

J. P. Xu received the B.S., M.S., and Ph.D. degrees in microelectronics from Huazhong University of Science and Technology (HUST), Wuhan, China, in 1982, 1984, and 1993, respectively.

From 1997 to 1999, he was a Postdoctoral Fellow with the University of Hong Kong and was engaged in study on thin gate dielectric for very large scale integration (VLSI) and gate dielectric of SiC MOS devices. Currently, he is a Professor with the Department of Electronic Science and Technology, HUST. His current research interests include the high- $\kappa$ gate dielectric, the modeling and simulation, the reliability of small-scaled $\mathrm{Si}$ and SiGe MOSFETs, and integrated sensors. 